\title{
Effect of Iron Source on Color and Appearance of Micronutrient- Fortified Corn Flour Tortillas
}

\author{
A. T. Richins \\ K. E. Burton \\ keburton5@yahoo.com \\ Heather F. Pahulu \\ Laura K. Jefferies \\ laura_jefferies@byu.edu \\ Michael L. Dunn
}

Follow this and additional works at: https://scholarsarchive.byu.edu/facpub

Part of the Food Science Commons, and the Nutrition Commons

\section{Original Publication Citation}

Richins, A. T., Burton, K. E., Pahulu, H. F. Jefferies, L, and Dunn, M. L. "Effect of iron source on color and appearance of micronutrient-fortified corn flour tortillas." Cereal Chemistry. 85.4 (28): 561-565.

\section{BYU ScholarsArchive Citation}

Richins, A. T.; Burton, K. E.; Pahulu, Heather F.; Jefferies, Laura K.; and Dunn, Michael L., "Effect of Iron Source on Color and Appearance of Micronutrient-Fortified Corn Flour Tortillas" (2008). Faculty Publications. 175.

https://scholarsarchive.byu.edu/facpub/175 


\title{
Effect of Iron Source on Color and Appearance of Micronutrient-Fortified Corn Flour Tortillas
}

\author{
A. T. Richins, ${ }^{1}$ K. E. Burton, ${ }^{1}$ H. F. Pahulu, ${ }^{1}$ L. Jefferies, ${ }^{1}$ and M. L. Dunn ${ }^{1,2}$
}

Iron deficiency anemia is a widespread occurrence. Consequently, iron is commonly added in cereal fortification programs. However, many iron sources cause undesirable sensory changes, especially color changes, in the food being fortified. This study evaluated the effect of different iron sources on CIE $L^{*} a * b *$ color values and sensory color perception in fortified corn tortillas. Corn masa flour was fortified with micronutrient premix containing vitamins, zinc, and one of eight iron compounds. Iron sources included ferrous fumarate $(\mathrm{F})$, ferrous sulfate $(\mathrm{S})$, ferric orthophosphate $(\mathrm{OP})$, ferrous lactate $(\mathrm{L})$, ferrous gluconate $(\mathrm{G})$, ferric pyrophosphate (PP), sodium iron (III)-EDTA, and A-131 electrolytic iron (E), with addition levels adjusted based on bioavailability. Control (Ct) samples were prepared with all micronutrients except iron. All iron-fortified tortillas had lower $L^{*}$ values and were significantly darker than control tortillas. Based on instrumental color values and Mexican regulatory recommendations, five treatments were selected for further testing. A difference-from-control sensory test was conducted comparing PP, E, OP, $\mathrm{F}$, and $\mathrm{S}$ with $\mathrm{Ct}$ tortillas. Sensory rankings were $\mathrm{Ct}>\mathrm{E}=\mathrm{PP}>\mathrm{OP}>\mathrm{F}>$ S. A-131 electrolytic iron is recommended for fortification of corn tortillas due to minimal effect on color and significantly lower cost than other iron sources evaluated.
Iron deficiency has been classified as the most prevalent micronutrient deficiency in the world (Dary et al 2002; Looker et al 2002). Inadequate iron intake leads to anemia in young children, adolescents, and women. And it leads to significant irreversible developmental delays and cognitive and motor deficits in infants, children, and adolescents (Looker et al 2002). Because of the widespread nature of iron deficiency, iron is considered a basic component in most food-fortification programs (Lynch 2005). Iron fortification of wheat flour is compulsory in Mexico (Secretaria de Salud 1996). However, a large percentage of the Mexican population consumes only minimal amounts of wheat-flour products. This consumption pattern is especially true among the portions of the population more nutritionally at risk, where the corn tortillas constitute $60-90 \%$ of cereal product intake (Villalpando 2004). Consequently, a 2005 regulatory proposal from the Mexican Comisión Federal para la Protección Contra Riesgos Sanitarios (COFEPRIS) included corn flour and nixtamalized corn flour as additional vehicles for mandatory fortification (Secretaria de Salud 2005). The initial proposal specified that iron be derived from ferrous sulfate or ferrous fumarate. Due to significant concern from industry regarding the potentially negative impact on color and stability associated with these more reactive iron sources, the proposal was modified to allow the use of other iron sources, as long as addition rates are adjusted to deliver a bioavailable amount of iron equivalent to that provided by ferrous sulfate or ferrous fumarate. The micronutrient levels in the proposed regulation are shown in Table I.

Hurrell (2002) reported that iron is the most problematic mineral to add to foods. Many of the compounds used as iron fortificants cause unacceptable color and flavor changes in the foods that are being fortified. For a fortification program to be successful, it is important that the combination of the fortificant and the vehicle are acceptable to the target population (Bovell-Benjamin and Guinard 2003). This requirement largely relates to sensory properties of the fortified food but also includes economic viability and efficacy or bioavailability.

\footnotetext{
${ }^{1}$ Department of Nutrition, Dietetics and Food Science, Brigham Young University, S-221 ESC, Provo, UT 84602.

${ }^{2}$ Corresponding author. Phone: 801.422.6670. Fax: 801.422.0258. E-mail address: Michael_dunn@byu.edu
}

doi:10.1094/CCHEM-85-4-0561

(c) 2008 AACC International, Inc.
A variety of iron forms with widely varying bioavailabilities and sensory effects have been evaluated in fortified foods. Moretti et al (2005) evaluated a number of different irons sources as fortificants in extruded rice grains, They found that the only iron source that did not cause significant color changes in the finished product was ferric pyrophosphate, whereas ferrous sulfate $(\mathrm{NaFe}$ EDTA) and electrolytic iron all had negative effects on color. The reduced iron, ferric ammonium citrate, ferrous sulfate, ferrous chloride, and ferrous gluconate had no significant effect on color in Arabic bread when added at Fe levels $\leq 50 \mathrm{mg} / \mathrm{lb}(110 \mathrm{mg} / \mathrm{kg})$ (Mohammad and Hallab 1973). Ferrous sulfate did significantly affect the color of flat bread (Alam et al 2007). Unfortified maize porridge had a brighter yellow color than porridge fortified with ferrous sulfate, ferrous bisglycinate, ferrous trisglycinate, or ironEDTA (Bovell-Benjamin et al 1999). Rosado et al (2005) examined the effect of micronutrient addition to corn flour tortillas and found that addition of iron in the form of elemental reduced iron did not cause tortilla color changes. However, Burton et al (2008) found that fortification of nixtamal corn tortillas with a micronutrient premix containing ferrous fumarate caused tortillas to be darker than unfortified control tortillas according to CIE lightdark $\left(L^{*}\right)$ values. Preliminary studies in tortilla mills in Mexico indicated that millers had adverse reactions to observable color differences in fortified tortillas when using ferrous fumarate as a fortificant (Dunn et al 2007).

The objective of this research was to evaluate the effects of different iron sources on the color and appearance of fortified corn tortillas when added at levels designed to yield approximately equivalent absorption based on bioavailability levels indicated in the literature.

TABLE I

Proposed Micronutrient Enrichment Levels for Nixtamalized Corn and Wheat Flours ${ }^{\mathrm{a}}$

\begin{tabular}{lcl}
\hline Nutrient & Min Level $(\mathbf{m g} / \mathbf{k g})^{\mathbf{b}}$ & Recommended Source $^{\mathbf{b}}$ \\
\hline Folic acid & 2 & Folic acid \\
Iron & 40 & Sulfate or fumarate \\
Thiamin & 5 & Thiamin mononitrate \\
Riboflavin & 3 & Riboflavin \\
Niacin & 35 & Nicotinamide \\
Zinc & 40 & Zinc oxide $^{\mathrm{c}}$ \\
\hline
\end{tabular}

a Norma Oficial Mexicana PROY-NOM-000-SSA1-2005.

${ }^{b}$ Minimum level of addition in flour.

${ }^{c}$ It is permissible to use other sources of iron and zinc as long as the amount added delivers a bioavailable amount equivalent to the recommended sources. 


\section{MATERIALS AND METHODS}

\section{Materials}

Corn tortillas were made from unfortified, instant corn masa flour (CMF) (Quaker, Chicago). Supplemental vitamins and zinc were added through a micronutrient premix consisting of: zinc oxide, riboflavin USP, thiamin mononitrate, folic acid, and nicotinic acid at levels indicated in Table I. Premix was provided by DSM Nutritional Products México, El Salto, Jalisco, México. Ferrous fumarate $(\mathrm{F})$, ferrous sulfate $(\mathrm{S})$, ferric orthophosphate $(\mathrm{OP})$, ferrous lactate $(\mathrm{L})$, ferrous gluconate $(\mathrm{G})$, and sodium iron (III)-EDTA (EDTA) were also provided by DSM. Other iron sources evaluated included ferric pyrophosphate (PP) (Paul Lohmann, Emmerthal, Germany) and A-131 electrolytic iron (E) (Research Products Co., Salina, KS).

\section{Tortilla Preparation}

Tortillas for initial colorimetric evaluation were prepared in a laboratory by adding the micronutrient premix and an individual iron source to $220 \mathrm{~g}$ of CMF in the amounts listed in Table II. Iron source addition was adjusted to provide an approximately equivalent absorbable dose of iron ( $40 \mathrm{mg} / \mathrm{kg}$ of flour), based on estimates of bioavailability available in the literature (Hurrell 1999; Hurrell et al 2002; Walter et al 2003; Bothwell and MacPhail 2004; Hernandez et al 2006). A control treatment was also prepared by adding the micronutrient premix without iron. The dry ingredients were mixed for $5 \mathrm{~min}$ using a bench-top planetary mixer with a flat, burnished paddle (Kitchen Aid, St. Joseph, MI). To make the masa, $230 \mathrm{~mL}$ of distilled water was added and mixed until dough was homogenous $(\approx 4 \mathrm{~min})$. The dough was removed and divided into 12 equal pieces that were formed into balls and then rolled to form a tortilla 6-in. diameter. Tortillas were cooked on an electric griddle for 20-25 sec on each side, then flipped again to cook the original side another 20-25 sec, mimicking a triple-pass oven. The tortillas were allowed to cool for $25 \mathrm{~min}$ before they were placed in plastic sample bags and refrigerated. Each batch of masa produced 12 tortillas. Two separate batches of fortified masa were prepared for each iron source evaluated, as well as for the control.

Tortillas prepared for sensory evaluation were produced in a similar manner to laboratory tortillas in $10-\mathrm{kg}$ batches. CMF was mixed with micronutrient premix + iron using a V-blender (twinshell dry blender) (Patterson-Kelly, E. Stroudsberg, PA). A commercial-scale planetary mixer with a dough-hook attachment was used to prepare the masa (model 0300, Hobart, Troy, OH). The masa was removed from the mixer and placed into 5-gal plastic pails with lids to be transported to a local commercial tortilleria. Tortillas were formed using a tortilla-forming machine (Maquinas Tortilladoras Celorio, Naucalpan, Mexico) which consisted of a mixer, extruder, and former in one unit. Formed tortillas were baked for 35-40 sec in a triple-pass, gas-fired oven, heated to $240^{\circ} \mathrm{C}$. While in the oven, tortillas were inverted twice. The cooked tortillas were then stacked and cooled for 10-15 min before being packaged in plastic bags and refrigerated. Two separate batches of each fortified treatment and control were prepared on consecutive days.

\section{Colorimeter}

Tortilla color was evaluated for both laboratory and tortilleria produced samples. As described above, instrumental results from laboratory-prepared tortillas were used to select treatments for the sensory panel. Tortilleria-produced tortillas were tested to ensure that these samples were similar in appearance to laboratory tortillas. Color was evaluated using a spectrophotometer (ColorFlex, Hunter Associates Laboratory, Reston, VA). An $18 \times 18$-cm glass plate was placed on the measuring port of the colorimeter followed by two stacked tortillas, double-baked side down. The tortillas were held in place using another glass plate. A white Hunter standardizing disk was placed on top to prevent transmittance and assure correct measurements. Each set of two tortillas was read three times, moving the tortillas from left to right in a straight line (Waliszewski et al 2004). For the laboratory-produced tortillas, the 12 tortillas from each batch were measured in stacked pairs. For the tortilleria-produced tortillas, 24 tortillas were randomly selected from each iron source and were measured in stacked pairs. This method provided 36 total readings per iron source. Average CIE $L^{*}$, red-green $\left(a^{*}\right)$, and blue-yellow $\left(b^{*}\right)$ colors were reported for each sample.

\section{Sensory Panel}

In addition to instrumental color measurement, a sensory panel was used to compare treatments. Five different treatments in addition to the control were presented to the panel. These included the three treatments (PP, E, and OP) that scored closest to the control in $L^{*}$ color score, as well as the two treatments $(\mathrm{F}$ and $\mathrm{S})$ that were specifically recommended in the proposed Mexican regulation for corn flour fortification. The sensory panel convened in the Food Science Sensory Laboratory of Brigham Young University (Provo, UT). Panelists were recruited from university employees and students and were selected based on their liking of and regular use of corn tortillas. Both genders were equally represented; there was approximately equal representation among age categories from 20 to $60+$ years. Fifty-six untrained panelists were presented simultaneously with a control tortilla and a stack of six other tortillas (five different iron variants and a blind control) separated by code-labeled sheets of paper. Sequence of presentation from top to bottom of the stack was balanced using a Williams design (MacFie et al 1989). Tortillas were brought to room temperature but were not reheated before serving. The panelists received samples through pass-through compartments in isolated

TABLE II

Iron Sources and Amount Used to Fortify Corn Flour for Tortillas ${ }^{\mathrm{a}}$

\begin{tabular}{|c|c|c|c|c|}
\hline Iron Source & $\mathrm{Fe}(\%)^{\mathrm{b}}$ & Relative Bioavailability (\%) & Iron Source (mg)/Flour (kg) & Iron (mg)/Flour (kg) \\
\hline Control (none) & - & - & 0 & 0 \\
\hline Ferrous sulfate & 30.0 & $100^{c}$ & 133.33 & 40.00 \\
\hline Ferrous fumarate & 33.0 & $100^{c}$ & 121.21 & 40.00 \\
\hline Ferric pyrophosphate & 25.0 & $48^{c}$ & 336.84 & 84.21 \\
\hline Ferric orthophosphate & 28.0 & $29^{c}$ & 501.25 & 140.35 \\
\hline A-131 electrolytic iron & 97.0 & $50^{\mathrm{d}}$ & 82.47 & 80.00 \\
\hline Ferrous lactate & 19.0 & $106^{\mathrm{c}}$ & 198.61 & 37.73 \\
\hline Ferrous gluconate & 12.0 & $89^{c}$ & 374.53 & 44.94 \\
\hline NaFe EDTA & 13.0 & $236^{\mathrm{e}}$ & 130.65 & 16.98 \\
\hline
\end{tabular}

a Approximate addition levels required to deliver bioavailable amount equivalent to $40 \mathrm{mg}$ of iron $/ \mathrm{kg}$ of corn flour.

b Based on specification sheets or Hurrell (1999).

${ }^{c}$ Hurrell (1999). Where ranges were given, midpoint in the range was used.

${ }^{\mathrm{d}}$ Hurrell et al (2002).

e Walter et al (2003); Bothwell and MacPhail (2004); Hernandez et al (2006). 
booths under fluorescent lighting. Panelists were instructed to hold each coded sample next to the control, evaluating the overall color and shade of each coded sample compared with the control, and then rate how different each sample was from the control, ignoring any scorch marks created by the tortilla oven. They were also informed that at least one of the coded samples could be the same as the control. Panelists marked the difference from control on a 0 to 9 scale, with 0 being "no difference" or same as control and 9 being "very different" or furthest from control. The same panelists evaluated batch 1 and batch 2 samples as separate events on the same day with different blinding codes. Data were collected using Compusense five v.4.6 (Guelph, ON, Canada) software and then exported to SAS for statistical analysis. The study was approved by the University Institutional Review Board for Human Subjects and panelists provided informed consent. Panelists received monetary compensation for their time.

\section{Data Analyses}

Data were analyzed with statistical software (SAS Institute, Cary, NC) using a mixed model analysis of variance (Proc Mixed) and the Tukey-Kramer procedure to determine significant differences among means. Significance level was 0.05 .

\section{RESULTS AND DISCUSSION}

\section{Color}

Results of instrumental color readings for both laboratory and tortilleria produced tortillas are shown in Table III. All ironfortified tortillas were significantly darker than control tortillas, regardless of iron source. $L^{*}$ color values for tortilleria-produced tortillas closely matched those of laboratory tortillas and showed a similar trend in rankings, with $\mathrm{PP}, \mathrm{E}$, and OP most closely matching the control. The $a^{*}$ color values for laboratory and tortilleria tortillas were -1.30 to 0.77 and -0.16 to 1.80 , respectively. Although significant differences were found among treatments, these differences may not be of practical significance because all values fell in such a narrow range. There did not appear to be any consistent pattern in the $a^{*}$ values due to fortification with iron. The $b^{*}$ color values followed a trend that was quite similar to $L^{*}$ values, with E, OP, and PP scoring closest to the control. However, for $b^{*}$ color values, EDTA treatments were more yellow than the control, whereas all other fortificants caused the tortillas to be less yellow.

The instrumental color effect of NaFeEDTA in this study contrasts with results found in iron-fortified maize porridge (BovellBenjamin et al 1999). In this research, unfortified control samples were compared with samples fortified with ferrous bisglycinate, ferrous trisglycinate, ferrous sulfate, and iron-EDTA using sensory descriptive analysis. The control porridge had a brighter yellow color than most fortified samples. The dullest-colored samples were those fortified with ferrous sulfate and iron-EDTA.
Although the effect of ferrous sulfate in porridge is consistent with the results reported in this study, EDTA seemed to have the opposite effect and caused tortillas to be much more yellow than the control. However, for $L^{*}$, iron-EDTA tortillas were significantly darker than control tortillas. This darkening effect may have caused them to appear duller during sensory analysis.

\section{Sensory Panel}

Results of the tortilla sensory panel are shown in Table IV. The difference-from-control scores for all iron treatments were significantly greater than differences from the "blind" control. E and PP were not significantly different and were most similar in color to the control. Sulfate and fumarate treatments, which were specifically recommended in the proposed 2005 Mexican regulation, were the most different from the control, with fumarate being the better of the two. These results are consistent with those reported by Moretti et al (2005), who found PP to have the least effect on sensory scores in extruded rice grains compared with EDTA and $\mathrm{S}$. However, they also reported that rice fortified with $\mathrm{E}$ received lower visual and colorimetric scores than PP. The data presented here indicates that $\mathrm{PP}$ and $\mathrm{E}$ were not significantly different in the sensory test, despite PP having an $L^{*}$ value significantly closer to the control. Possibly the greater inherent coloration of the tortilla compared with rice resulted in less visible change when using $\mathrm{E}$ as a fortificant.

$L^{*}$ and $b^{*}$ color values for laboratory tortillas were strongly correlated with sensory scores $\left(r^{2}=0.82\right.$ and 0.78 , respectively). It appears that instrumental $L^{*}$ and $b^{*}$ color may be good predictors of discernible sensory differences in corn tortillas. As we described previously, $a^{*}$ values varied widely among treatments and thus were not strongly correlated with sensory appearance.

\section{DISCUSSION}

Based on instrumental color values and sensory appearance scores, E and PP appear to be the best candidates for iron fortification of corn masa tortillas. However, cost and bioavailability

TABLE IV

Sensory Scores for Iron-Fortified Corn-Flour Tortillas ${ }^{\text {a }}$

\begin{tabular}{lc}
\hline Iron Source & Score \\
\hline Control (blind) & $1.3 \mathrm{a}$ \\
Ferrous fumarate & $4.0 \mathrm{~d}$ \\
Ferric orthophosphate & $3.0 \mathrm{c}$ \\
Ferrous sulfate & $6.3 \mathrm{e}$ \\
Ferric pyrophosphate & $2.4 \mathrm{~b}$ \\
A-131 electrolytic iron & $2.2 \mathrm{~b}$ \\
\hline
\end{tabular}

${ }^{a}$ Scores indicate difference from control on a point scale of 0 (no difference or same as control) to 9 (very different or furthest from control). Values followed by the same letter are not significantly different $(P>0.05)$. Standard error of the mean $=0.193$.

TABLE III

$L^{*} a^{*} b^{*}$ Color Values of Corn Tortillas Fortified with Different Iron Sources ${ }^{\text {a }}$

\begin{tabular}{|c|c|c|c|c|c|c|}
\hline Iron Source & $L *($ lab) & $L *($ tort $)$ & $a^{*}($ lab) & $a^{*}($ tort $)$ & $b *(\mathbf{l a b})$ & $b *($ tort $)$ \\
\hline Control (none) & $71.25 \mathrm{a}$ & $71.51 \mathrm{a}$ & $0.42 b$ & $0.99 \mathrm{c}$ & $27.39 b$ & $20.85 a$ \\
\hline Ferrous sulfate & $60.69 f$ & $60.12 \mathrm{~d}$ & $-1.30 \mathrm{f}$ & $-0.16 \mathrm{e}$ & $19.45 \mathrm{e}$ & $16.20 \mathrm{~d}$ \\
\hline Ferrous fumarate & $65.78 \mathrm{e}$ & $65.12 \mathrm{c}$ & $0.01 \mathrm{~cd}$ & $0.41 \mathrm{~d}$ & $22.78 d$ & $17.48 \mathrm{c}$ \\
\hline Ferric pyrophosphate & $69.18 b$ & $67.05 \mathrm{~b}$ & $0.47 \mathrm{~b}$ & $1.36 \mathrm{~b}$ & $25.79 \mathrm{c}$ & $20.47 \mathrm{ab}$ \\
\hline Ferric orthophosphate & $67.13 \mathrm{~d}$ & $65.76 c$ & $0.77 \mathrm{a}$ & $1.31 \mathrm{~b}$ & $25.80 \mathrm{c}$ & $19.87 b$ \\
\hline A-131 electrolytic iron & $68.11 \mathrm{c}$ & $66.99 b$ & $-0.16 \mathrm{~d}$ & $1.80 \mathrm{a}$ & $24.92 \mathrm{c}$ & $20.32 \mathrm{ab}$ \\
\hline Ferrous lactate & $58.06 \mathrm{~h}$ & - & $-1.26 f$ & - & $19.86 \mathrm{e}$ & - \\
\hline Ferrous gluconate & $59.24 \mathrm{~g}$ & - & $-0.87 \mathrm{e}$ & - & $19.35 \mathrm{e}$ & - \\
\hline NaFe EDTA & $66.16 \mathrm{e}$ & - & $0.28 \mathrm{bc}$ & - & $42.76 a$ & - \\
\hline Standard error of the mean & 0.218 & 0.262 & 0.063 & 0.051 & 0.242 & 0.155 \\
\hline
\end{tabular}

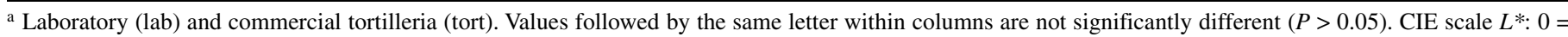
black, $100=$ white; $a^{*}$ : negative values indicate green, positive values indicate red; $b^{*}$ : negative values indicate blue, positive values indicate yellow. 
must also be taken into consideration when choosing an ideal iron source (Whittaker 1998). Electrolytic iron has a significantly lower cost than the other iron sources but has a lower bioavailability than sulfate or fumarate (Hurrell 1999). The bioavailability of electrolytic iron reported in the literature varies greatly. One study found that maize porridge fortified with $\mathrm{E}$ did not decrease the prevalence of iron-deficiency anemia in children and did not improve any of the iron-status indicators evaluated (Andang'o et al 2007). Swain et al (2003) reported that A-131 electrolytic iron had $54 \%$ of the bioavailability of ferrous sulfate based on rat studies. However, more recent research has shown $\mathrm{E}$ to be effective in improving iron-status in humans. Hoppe et al (2006) found that A-131 electrolytic iron had $65 \%$ absorption in Swedish subjects consuming fortified wheat rolls, compared with ferrous sulfate. In a study comparing elemental iron powders using in vitro solubilities and human efficacy trials, electrolytic iron had 51-73\% effective dissolution depending on the source. The most soluble electrolytic source was A-131, which resulted in $77 \%$ relative bioavailability compared with ferrous sulfate in Thai women consuming fortified wheat-based snacks (Zimmerman et al 2005; Lynch and Bothwell 2007). Moretti et al (2006) stated that relative bioavailabilities vary widely with food matrix and iron status. Thus, it may be difficult to compare studies of different fortified foods among different populations. However, these findings indicate that electrolytic iron can be effectively used as an iron fortificant. Addition of A-131 electrolytic iron at double the intended addition rate (the rate used in this study) has been specifically recommended for fortification of cereal food staples when ferrous sulfate and ferrous fumarate cause unacceptable changes in the color of fortified foods (SUSTAIN 2001; Hurrell et al 2002).

Iron-EDTA has received attention because it has reportedly high bioavailability, especially in cereal-based foods (Hurrell et al 2000). This was shown specifically in corn-masa tortillas, where NaFeEDTA had higher bioavailability than ferrous fumarate, ferrous bisglycinate, ferrous sulfate, and reduced iron (Davidsson et al 2002; Walter et al 2003). This compound also has little effect on the sensory qualities of some foods such as instant noodles (Kongkachuichai 2007). However, in our study, NaFe EDTA significantly affected tortilla color even when added at less than half the iron dosage of iron sulfate. This result is reinforced by the study of Duarte-Vazquez et al (2004), who reported that $\mathrm{NaFe}$ EDTA had a greater effect on corn tortilla color than reduced iron, ferrous sulfate, and ferrous fumarate (Duarte-Vazquez et al 2004). In addition to its negative effect on tortilla color, NaFe EDTA is also more expensive, with a cost more than double that of ferrous sulfate (personal communication).

Although electrolytic iron may have reduced bioavailability compared with iron-EDTA, it has the least effect on tortilla appearance. Additionally, its lower cost makes it economically feasible to incorporate the iron at a higher level to account for the lower bioavailability. Despite the importance of other factors, one of the initial hurdles to overcome in any fortification program is consumer acceptance stemming from sensory effects and cost (Salgueiro et al 2002). On this basis, it appears that electrolytic iron may be the most suitable fortificant when incorporated at the higher recommended levels.

\section{CONCLUSIONS}

All iron fortificants used in this experiment significantly affected both the instrumental and sensory color of fortified tortillas made from corn flour. Of these compounds, ferric pyrophosphate and A-131 electrolytic iron caused the least amount of change, even when added at double the iron dosage level of ferrous sulfate. A-131 electrolytic iron has a significantly lower cost than most other iron sources. Furthermore, a sensory test using 100 Mexican consumers indicated that there were no significant differences in acceptability of color, appearance, aroma, texture, or flavor in side-by-side comparisons of tortillas fortified with electrolytic iron at levels used in this study and unfortified control samples (Dunn et al 2007). Tortillas fortified with electrolytic iron could be a viable option to reduce the prevalence of iron deficiency in the Mexican population.

\section{ACKNOWLEDGMENTS}

This project was conducted in collaboration with SUSTAIN (www. sustaintech.org), through a grant to SUSTAIN from the Bill \& Melinda Gates Foundation. We wish to express gratitude to DSM Nutritional Products Mexico for advice and provision of the micronutrient premixes.

\section{LITERATURE CITED}

Alam, S., Shah, H. U., and Saleemullah, R. A. 2007. Comparative studies on storage stability of ferrous iron in whole wheat flour and flat bread (naan). Int. J. Food Sci. Nutr. 58:54-62.

Andang'o P. E. A., Osendarp, S. J. M., Ayah, R., West, C. E., Mwaniki, D. L., De Wolf, C. A., Kraaijenhagen, R., Kok, F. J., and Verhoef, H. 2007. Efficacy of iron-fortified whole maize flour on iron status of schoolchildren in Kenya: A randomized controlled trial. Lancet 369:1799-1806.

Bothwell, T. H., and MacPhail, A. P. 2004. The potential role of NaFeEDTA as an iron fortificant. Int. J. Vitam. Nutr. Res. 74:421-434.

Bovell-Benjamin, A. C., and Guinard, J.-X. 2003. Novel approaches and application of contemporary sensory evaluation practices in iron fortification programs. Crit. Rev. Food Sci. Nutr. 43:379-400.

Bovell-Benjamin, A. C., Allen, L. H., Frankel, E. N., and Guinard, J.-X. 1999. Sensory quality and lipid oxidation of maize porridge as affected by iron amino acid chelates and EDTA. J. Food Sci. 64:371-376.

Burton, K. E., Steele, F. M., Jefferies, L., Pike, O. A., and Dunn, M. L. 2008. Effect of micronutrient fortification on nutritional and other properties of nixtamal tortillas. Cereal Chem. 85:70-75.

Dary, O., Freire, W., and Kim, S. 2002. Iron compounds for food fortification: Guidelines for Latin America and the Caribbean 2002. Nutr. Rev. 60:S50-S61.

Davidsson, L., Dimitriou, T., Boy, E., Walczyk, T., and Hurrell, R. F. 2002. Iron bioavailability from iron-fortified Guatemalan meals based on corn tortillas and bean paste. Am. J. Clin. Nutr. 75:535-539.

Duarte-Vazquez, M. A., Olivares, G., Cassis, L., and Rosado, J. L. 2004. Studies on micronutrients stability and acceptability of Mexican tortillas fortified with different sources of iron. Annual meeting paper. IFT: Chicago.

Dunn, M. L., Serna-Saldivar, S. O., and Turner, E. H. 2007. Industrial approaches to micronutrient fortification of traditional nixtamal tortillas. Cereal Foods World 52:240-248.

Hernandez, M., Sousa, V., Villalpando, S., Moreno, A., Montalvo, I., and Lopez-Alarcon, M. 2006. Cooking and Fe fortification have different effects on Fe bioavailability of bread and tortillas. J. Am. Coll. Nutr. 25:20-25

Hoppe, M., Hulthén, L., and Hallberg, L. 2006. The relative bioavailability in humans of elemental iron powders for use in food fortification. Eur. J. Nutr. 45:37-44

Hurrell, R. F., ed. 1999. Iron. Pages 54-93 in: The Mineral Fortification of Foods. Leatherhead: London.

Hurrell, R. F. 2002. How to ensure adequate iron absorption from ironfortified food. Nutr. Rev. 60:S7-S15.

Hurrell, R. F., Reddy, M. B., Burri, J., and Cook, J. D. 2000. An evaluation of EDTA compounds for iron fortification of cereal-based foods. Br. J. Nutr. 84:903-910.

Hurrell, R. F., Bothwell, T., Cook, J. D., Dary, O., Davidsson, L., Fairweather-Tait, S., Hallberg, L., Lynch, S., Rosado, J., Walter, T., and Whittaker, P. 2002. The usefulness of elemental iron for cereal flour fortification: a SUSTAIN task force report. Nutr. Rev. 60:391-406.

Kongkachuichai, R., Kounhawej, A., Chavasit, V., and Charoensiri, R. 2007. Effects of various iron fortificants on sensory acceptability and shelf-life stability of instant noodles. Food Nutr. Bull. 28:165-172.

Looker, A. C., Cogswell, M. E., and Gunter, E. W. 2002. Iron deficiency-United States, 1999-2000. Morb. Mortal. Wkly. Rep. 51:897899.

Lynch, S. R. 2005. The impact of iron fortification on nutritional anemia. Best Pract. Res. Clin. Haematol. 18:333-346.

Lynch, S. R., Bothwell, T. 2007. SUSTAIN task force on iron powders. A 
comparison of physical properties, screening procedures and a human efficacy trial for predicting the bioavailability of commercial elemental iron powders used for food fortification. Int. J. Vitam. Nutr. Res. 77:107-124.

MacFie, H. J., Bratchell, N., Greenhoff, K., and Vallis, L. V. 1989. Design to balance the effect of order of presentation and first order carry-over effects in hall tests. J. Sens. Stud. 4:129-148.

Mohammad, N., and Hallab, A. H. 1973. Effect of iron enrichment of flour on the dough characteristics and organoleptic qualities of Arabic bread. Pak. J. Sci. Ind. Res. 16:115-119.

Moretti, D., Lee, T.-C., Zimmermann, M. B., Nuessli, J., and Hurrell, R. F. 2005. Development and evaluation of iron-fortified extruded rice grains. J. Food Sci. 70:S330-S336.

Moretti, D., Zimmermann, M. B., Wegmüller, R., Walczyk, T., Zeder, C., and Hurrell, R. F. 2006. Iron status and food matrix strongly affect the relative bioavailability of ferric pyrophosphate in humans. Am. J. Clin. Nutr. 83:632-638.

Rosado, J. L., Cassis, L., Solano, L., and Duarte-Vazquez, M. A. 2005. Nutrient addition to corn masa flour: Effect on corn flour stability, nutrient loss, and acceptability of fortified corn tortillas. Food Nutr. Bull. 26:266-272.

Salgueiro, M. J., Zubillaga, M., Lysionek, A., Caro, R., Weill, R., and Boccio, J. 2002. Fortification strategies to combat zinc and iron deficiency. Nutr. Rev. 60:52-58.

Secretaria de Salud. 1996. Norma Oficial Mexicana NOM-147-SSA11996. Secretaria de Salud, Mexico.
Secretaria de Salud. 2005. ANTEPROYECTO de Norma Oficial Mexicana PROY-NOM-000-SSA1-2005. Secretaria de Salud, Mexico.

SUSTAIN. 2001. Guidelines for iron fortification of cereal food staples. Available online at: www.sustaintech.org/publications/pubm7.pdf. SUSTAIN: Washington, DC.

Swain, J. H., Newman, S. M., and Hunt, J. R. 2003. Bioavailability of elemental iron powders to rats is less than bakery-grade ferrous sulfate and predicted by iron solubility and particle surface area. J. Nutr. 133:3546-3552.

Villalpando, S. 2004. Tortilla fortification working group meeting. El problema de la biodisponibildad de hierro en harina de maiz nixtamalizada. National Institute of Public Health: Mexico City.

Waliszewski, K., Estrada, Y., and Pardio, V. 2004. Sensory properties changes of fortified nixtamalized corn flour with lysine and tryptophan during storage. Plant Foods Hum. Nutr. 59:51-54.

Walter, T., Pizarro, F., and Olivares, M. 2003. Iron bioavailability in cornmasa tortillas is improved by the addition of disodium EDTA. J. Nutr. 133:3158-3161.

Whittaker, P. 1998. Iron and zinc interactions in humans. Am. J. Clin. Nutr. 57:190-194.

Zimmermann, M. B., Winichagoon, P., Gowachirapant, S., Hess, S. Y., Harrington, M., Chavasit, V., Lynch, S. R., and Hurrell, R. F. 2005. Comparison of the efficacy of wheat-based snacks fortified with ferrous sulfate, electrolytic iron, or hydrogen-reduced elemental iron: Randomized, double-blind, controlled trial in Thai women. Am. J. Clin. Nutr. 82:1276-1282.

[Received February 13, 2008. Accepted April 7, 2008.] 